\title{
Studi Kolonisasi Semut Hitam (Dolichoderus sp.) Pada Perkebunan Kakao
}

\section{The study of ants colonization (Dolichoderus sp.) on Cocoa Plantations}

\author{
Adit Irawan $^{1}$, Umrah $^{1}$ dan Annawaty ${ }^{1}$ \\ ${ }^{1}$ Jurusan Biologi FMIPA, Universitas Tadulako \\ Kampus Bumi Tadulako Jl. Soekarno-Hatta Km.9 Palu, Sulawesi Tengah 94118
}

\begin{abstract}
The study of ants colonization (Dolichoderus sp.) on cocoa plantations, is one part of the role of biological resources in pest control. The aim of this research was to know the preferences of Dolichoderus sp. to feed from honey dew and bee honey, to become an attraction in forming colonies on artificial nests. Observations made from April to May 2015. The study was conducted on 20 randomly selected cocoa trees regardless age of cocoa trees and unspecified varieties. Two different treatments were administered on artificial nests, the two treatments used were artificial nests with honey from bees and nests placed on fruits with white fleas. Observation parameters include the formation ant colonies in artificial nests, the presence of queens in new colonies and ant preference to feed. The ants migrate slowly as seen from the time it takes the queen to migrate ie in the third week of observation. Feed from honey dew used is not effective in making black ants form colonies in artificial nests, judging by the presence of worker ants and queen ants in artificial nests. Honey feed from bees attracts the presence of black worker ants more than honey dew from white fleas, because of the scent of honey that spreads fast and the sugar content in honey is high.
\end{abstract}

\section{Keywords: Dolichoderus sp., Cocoa, Colony}

\begin{abstract}
ABSTRAK
Studi kolonisasi semut hitam (Dolichoderus sp.) pada perkebunan kakao, merupakan salah satu bagian dari peran sumberdaya hayati dalam pengendalian hama. Penelitian bertujuan untuk mengetahui preferensi Dolichoderus sp. terhadap pakan dari embun madu dan madu lebah, untuk menjadi daya tarik dalam membentuk koloni pada sarang buatan. Pengamatan dilakukan pada bulan April-Mei 2015. Penelitian dilakukan pada 20 pohon kakao yang dipilih secara acak tanpa memperhatikan usia pohon kakao dan varietasnya tidak ditentukan. Dua perlakuan yang berbeda diberikan pada sarang buatan, kedua perlakuan yang digunakan adalah sarang buatan dengan pemberian madu dari lebah dan sarang yang ditempatkan pada buah yang terdapat kutu putih. Parameter pengamatan meliputi terbentuknya koloni semut pada sarang buatan, kehadiran ratu pada koloni baru dan preferensi semut terhadap pakan. Semut hitam melakukan migrasi dengan lambat yang dilihat dari waktu yang dibutuhkan ratu untuk migrasi yaitu pada minggu ketiga pengamatan. Pakan dari embun madu yang digunakan tidak efektif dalam membuat semut hitam membentuk koloni pada sarang buatan, dilihat dari jumlah kehadiran semut pekerja dan
\end{abstract}


semut ratu pada sarang buatan. Pakan madu dari lebah menarik kehadiran semut hitam pekerja lebih banyak dari embun madu dari kutu putih, karena aroma madu yang menyebar cepat dan kandungan gula pada madu yang tinggi.

\section{Kata kunci : Dolichoderus sp., Kakao, Koloni}

\section{PENDAHULUAN}

Kakao telah lama dibudidayakan secara komersial oleh manusia sebagai komoditas utama perekonomian. Sebagai komoditi utama produksi biji kakao yang diperoleh masih belum optimal dan bahkan sering mengalami penurunan. Turunnya produksi biji kakao ini disebabkan oleh hama yang merupakan masalah utama dalam budidaya tanaman kakao, hama utama yang menurunkan produksi kakao adalah serangga. Jenis serangga pada tanaman kakao yang biasanya menjadi hama yaitu penggerek buah kakao (Conopomorpha cramella Snellen), kepik penghisap buah kakao (Helopeltis antonii), ulat kilan (Hyposidra talaca Walker), penggerek cabang atau batang (Zeuzera sp.), dan ulat api Darna trima (Sulistyowati, 1988).

Hama penggerek buah Conopomorpha cramerella dan hama penghisap buah Helopeltis antonii merupakan dua hama utama yang menurunkan produksi biji kakao. Berbagai cara telah dilakukan para petani untuk mengatasi masalah hama tersebut, yang paling banyak digunakan para petani adalah insektisida (racun serangga), namun penggunaan insektisida ini memiliki dampak negatif antara lain yaitu: mencemari lingkungan, menganggu kesehatan petani, membunuh fauna dan fauna non target, dan menimbulkan resistensi hama. Salah satu cara yang efektif adalah pengendalian hama secara biologis, yaitu dengan memanfaatkan atau memanipulasi musuh alami hama, baik yang berupa patogen, predator maupun parasitoid yang mampu membunuh atau menekan populasi hama secara alami.

Musuh alami yang dinilai mampu mengatasi serangan hama pada buah kakao yaitu semut hitam (Dolichoderus sp.). Semut hitam (Dolichoderus sp., yang dulu dikenal dengan nama Dolichoderus bituberculatus) telah lama diketahui sebagai agen pengendali hayati hama pada tanaman kakao, keberadaan populasi semut hitam pada tanaman kakao dipengaruhi oleh adanya sumber makanan. Beberapa semut memakan serangga-serangga kecil yang mereka tangkap, serangga-serangga mati yang dapat mereka temukan, atau nektar dari tumbuhan, namun pada semut hitam mereka bersimbiosis dengan kutu putih seperti Planococcus liliacinus dan Pseudococcus citri agar dapat memakan cairan yang berasal dari sekresi kutu putih. 
Cairan yang disebut "embun madu" inilah yang berperan sebagai makanan utama semut hitam (Ho and Khoo, 1997).

Sebagai makanan utama semut hitam jumlah populasi kutu putih tidak berimbang dengan luas areal perkebunan kakao yang mengakibatkan semut hitam kekurangan makanan, akibatnya jumlah semut hitam yang ada dalam areal perkebunan itu tidak cukup untuk melindungi buah kakao karena semut hitam tidak dapat meningkatkan pertumbuhan koloninya, selain manfaat kutu putih yang besar terhadap kelangsungan hidup semut hitam pada perkebunan kakao, kutu putih juga memiliki dampak negatif terhadap tanaman yaitu dapat menyebabkan tumbuhnya cendawan atau jamur pada daun sehingga akan merusak daun. Jamur tersebut akan menutupi daun sehingga dapat menghalangi cahaya matahari yang jatuh pada daun yang dapat mengganggu proses fotosintesis tanaman. Populasi kutu putih dalam jumlah besar bahkan dapat mengakibatkan kerontokan daun.

Mengatasi dampak negatif dari kutu putih tersebut maka pada penelitian pakan alternatif yang diberikan kepada koloni semut hitam berdasarkan pada embun madu sebagai makanan utama semut hitam, yaitu pakan alternatif yang mengandung glukosa.

Dari uraian di atas maka perlu adanya kelanjutan untuk melaksanakan penelitian yang bertujuan mengetahui tahap kolonisasi semut hitam dan pakan alternatif yang sebaiknya digunakan agar mempercepat dalam pembentukan koloni semut hitam.

\section{BAHAN DAN METODE}

Penelitian dilakukan di Kebun Kakao yang berlokasi di Desa Pantoloan Kecamatan Palu Utara yang dilakukan sejak bulan Maret sampai bulan Mei 2015. Percobaan dilakukan dengan menggunakan Rancangan Acak Kelompok (RAK) mencakup dua perlakuan yang akan diberikan pada sarang. Penelitian dilakukan pada dua kebun kakao. Kedua perlakuan yang digunakan adalah: Sarang dengan pakan "embun madu" dari kutu putih dan sarang dengan pakan madu asli. Kebun percobaan dipilih lahan tanaman kakao yang usianya berbeda dengan varietasnya yang tidak ditentukan, dan memiliki jarak tanam 2 x 2 meter. Perkebunan kakao tempat penelitian berada di daerah dengan ketinggian \pm 650 meter dari permukaan laut, memiliki curah hujan rata-rata 14-16 $\mathrm{mm} / \mathrm{tahun}$, dan suhu antara 20-30 C.

Sarang terbuat dari bambu yang di dalamnya dimasukkan daun kelapa kering yang banyak terdapat disekitar areal perkebunan. Sarang buatan mempunyai ukuran panjang $30 \mathrm{~cm}$ dan mulut sarang mempunyai ukuran panjang $10 \mathrm{~cm}$. Sarang dipasang secara acak pada 38 pohon kakao. Pemasangan antara sarang dengan bahan pakan yang sama diusahakan tidak saling 
berdekatan. Sarang dipasang pada cabang tanaman kakao dan diikat dengan tali rafia. Sarang dipasang pada ketinggian kurang lebih 1,5 meter dari permukaan tanah. Perlakuan yang diberikan adalah dengan menggunakan dua bahan pakan yang berbeda untuk melihat proses kolonisasi semut hitam (Dolichoderus sp.) di sarang buatan. Kedua bahan pakan yang diujikan tersebut adalah: madu asli dan "embun madu" dari kutu putih. Dimana kadar madu yang digunakan adalah 5\% dengan takaran sebanyak $100 \mathrm{ml}$ setiap sarang. Pengamatan dilakukan dengan membongkar sarang dan mengamati semut hitam di tiap perlakuan. Pengamatan dilakukan dengan menggunakan lup atau kaca pembesar.

\section{HASIL}

Tabel 1 Hasil pengamatan Dolichoderus sp. dengan perlakuan embun madu

\begin{tabular}{cccccc}
\hline $\begin{array}{c}\text { Poho } \\
\mathbf{n}\end{array}$ & $\begin{array}{c}\text { Semut } \\
\text { Pekerj } \\
\mathbf{a}\end{array}$ & $\begin{array}{c}\text { Semu } \\
\mathbf{t} \\
\text { Ratu }\end{array}$ & $\begin{array}{c}\text { Semu } \\
\text { Janta } \\
\mathbf{n}\end{array}$ & $\begin{array}{c}\text { Pup } \\
\mathbf{a}\end{array}$ & $\begin{array}{c}\text { Larv } \\
\mathbf{a}\end{array}$ \\
\hline $\mathrm{P}_{1}$ & 260 & 0 & 0 & 0 & 0 \\
\hline $\mathrm{P}_{2}$ & 320 & 0 & 0 & 0 & 0 \\
\hline $\mathrm{P}_{3}$ & 0 & 0 & 0 & 0 & 0 \\
\hline $\mathrm{P}_{4}$ & 272 & 0 & 0 & 0 & 0 \\
\hline $\mathrm{P}_{5}$ & 236 & 0 & 0 & 0 & 0 \\
\hline $\mathrm{P}_{6}$ & 862 & 0 & 0 & 0 & 0 \\
\hline $\mathrm{P}_{7}$ & 1120 & 1 & 0 & 0 & 0 \\
\hline $\mathrm{P}_{8}$ & 1860 & 1 & 0 & 0 & 0 \\
\hline $\mathrm{P}_{9}$ & 261 & 0 & 0 & 0 & 0 \\
\hline $\mathrm{P}_{10}$ & 3431 & 1 & 0 & 0 & 0 \\
\hline
\end{tabular}

Tabel 2 Hasil pengamatan Dolichoderus sp. pada perlakuan madu lebah

\begin{tabular}{cccccc}
\hline $\begin{array}{c}\text { Poho } \\
\mathbf{n}\end{array}$ & $\begin{array}{c}\text { Semut } \\
\text { Pekerj } \\
\mathbf{a}\end{array}$ & $\begin{array}{c}\text { Semu } \\
\mathbf{t} \\
\text { Ratu }\end{array}$ & $\begin{array}{c}\text { Semu } \\
\text { Janta } \\
\mathbf{n}\end{array}$ & $\begin{array}{c}\text { Pup } \\
\mathbf{a}\end{array}$ & $\begin{array}{c}\text { Larv } \\
\mathbf{a}\end{array}$ \\
\hline $\mathrm{P}_{1}$ & 182 & 0 & 0 & 0 & 0 \\
\hline
\end{tabular}

\begin{tabular}{cccccc}
\hline $\mathrm{P}_{2}$ & 127 & 0 & 0 & 0 & 0 \\
\hline $\mathrm{P}_{3}$ & 2340 & 1 & 0 & 0 & 0 \\
\hline $\mathrm{P}_{4}$ & 197 & 0 & 0 & 0 & 0 \\
\hline $\mathrm{P}_{5}$ & 161 & 0 & 0 & 0 & 0 \\
\hline $\mathrm{P}_{6}$ & 2467 & 1 & 0 & 0 & 0 \\
\hline $\mathrm{P}_{7}$ & 830 & 0 & 0 & 0 & 0 \\
\hline $\mathrm{P}_{8}$ & 3820 & 1 & 0 & 0 & 0 \\
\hline $\mathrm{P}_{9}$ & 134 & 0 & 0 & 0 & 0 \\
\hline $\mathrm{P}_{10}$ & 1646 & 1 & 0 & 0 & 0 \\
\hline
\end{tabular}

Pengamatan terhadap semut hitam (Dolichoderus sp.) di dalam sarang menunjukkan bahwa pada minggu pertama (Tabel 4), sarang buatan dengan dua perlakuan yaitu embun madu dari kutu putih dan madu lebah belum dilihat kehadiran ratu.

Keberadaan semut pekerja di sarang menunjukkan bahwa koloni terbentuk secara migrasi, di mana semut pekerja telah datang ke sarang tersebut sebelum semut ratu datang. Hal ini dikarenakan semut pekerja yang ada pada minggu pertama bukan merupakan keturunan hasil perkawinan ratu dan semut jantan yang baru tersebut. Semut pekerja yang berada di dalam sarang berasal dari koloni lain yang telah datang sebelumnya atau melakukan migrasi sebelum ratu.

Tabel 3 Perbandingan kehadiran Dolichoderus sp. pada perlakuaan embun madu dan madu lebah

\begin{tabular}{ccc}
\hline Pohon & $\begin{array}{c}\text { Embun } \\
\text { madu dari } \\
\text { Kutu putih }\end{array}$ & $\begin{array}{c}\text { Madu } \\
\text { lebah }\end{array}$ \\
\hline $\mathrm{P}_{1}$ & 260 & 182 \\
\hline $\mathrm{P}_{2}$ & 320 & 127 \\
\hline $\mathrm{P}_{3}$ & 0 & 2340 \\
\hline $\mathrm{P}_{4}$ & 272 & 197 \\
\hline $\mathrm{P}_{5}$ & 236 & 161 \\
\hline $\mathrm{P}_{6}$ & 862 & 2467 \\
\hline $\mathrm{P}_{7}$ & 1120 & 830 \\
\hline
\end{tabular}




\begin{tabular}{ccc}
\hline $\mathrm{P}_{8}$ & 1860 & 3820 \\
\hline $\mathrm{P}_{9}$ & 261 & 134 \\
\hline $\mathrm{P}_{10}$ & 3431 & 1646 \\
\hline Jumlah rata-rata & 862,2 & 1190,4 \\
\hline
\end{tabular}

Berdasarkan hasil perhitungan yang dilakukan setelah pengamatan koloni semut hitam pada sarang buatan dengan perlakuan "embun madu" didapatkan data bahwa dalam setiap sarang buatan, sebaran semut hitam tidak merata, dilihat dari beberapa sarang buatan yang memiliki semut hitam pekerja (Tabel 1) yaitu sarang buatan $P_{1}$ (Pohon 1), sarang buatan $\mathrm{P}_{2}$, sarang buatan $\mathrm{P}_{4}$, sarang buatan $\mathrm{P}_{5}$, sarang buatan $\mathrm{P}_{6}$, sarang buatan $\mathrm{P}_{7}$, sarang buatan $\mathrm{P}_{8}$, sarang buatan $\mathrm{P}_{9}$, sarang buatan $\mathrm{P}_{10}$, jumlah sembilan sarang buatan yang terdapat populasi semut hitam pekerja, koloni yang terbentuk pada tiga sarang buatan yaitu sarang buatan $\mathrm{P}_{7}$, sarang buatan $\mathrm{P}_{8}$, sarang buatan $\mathrm{P}_{10}$ (Tabel 1), terbentuknya koloni terlihat dari kehadiran semut ratu pada tiga sarang buatan ini, tahapan dalam kolonisasi adalah tahap perluasan, menyatakan tahap perluasan ditandai dengan keberadaan semut ratu di dalam sarang (Holldobler and Wilson, 1990). Sarang buatan yang tidak dilihat kehadiran semut hitam pekerja pada sarang buatan $\mathrm{P}_{3} \quad$ (Tabel 1), jawaban mengapa sarang buatan ini tidak ada kehadiran semut hitam pekerja, kami tidak menemukan penyebab utamanya dilapangan. Sarang buatan yang kehadiran semut hitam pekerja dapat dilihat yaitu

sarang buatan $\mathrm{P}_{1}$, sarang buatan $\mathrm{P}_{2}$, sarang buatan $\mathrm{P}_{4}$, sarang buatan $\mathrm{P}_{5}$, sarang buatan $\mathrm{P}_{6}$, sarang buatan $\mathrm{P}_{9}$ belum menjadi sebuah koloni karena tidak ditemukan kehadiran semut ratu pada sarang buatan ini. Hasil pengamatan pada sarang buatan $\mathrm{P}_{7}$, sarang buatan $\mathrm{P}_{8}$, sarang buatan $\mathrm{P}_{10}$ kehadiran semut ratu dapat dilihat (Tabel 1) yang berarti koloni terbentuk.

Pengamatan yang dilakukan pada sarang buatan dengan perlakuan madu dari lebah (Tabel 2) pada sarang buatan $\mathrm{P}_{1}$, sarang buatan $\mathrm{P}_{2}$, sarang buatan $\mathrm{P}_{3}$, sarang buatan $\mathrm{P}_{4}$, sarang buatan $\mathrm{P}_{5}$, sarang buatan $\mathrm{P}_{6}$, sarang buatan $\mathrm{P}_{7}$, sarang buatan $\mathrm{P}_{8}$, sarang buatan $\mathrm{P}_{9}$, sarang buatan $\mathrm{P}_{10}$ kehadiran semut hitam pekerja dapat dilihat. Sepuluh sarang buatan yang diamati kehadiran semut hitam pekerja dapat dilihat, empat sarang buatan yang diamati koloni semut hitam terbentuk yaitu sarang buatan $\mathrm{P}_{3}$, sarang buatan $\mathrm{P}_{6}$, sarang buatan $\mathrm{P}_{8}$, dan sarang buatan $\mathrm{P}_{10}$ (Tabel 2) ditandai dengan kehadiran semut ratu.

Berdasarkan hasil pengamatan terhadap kedatangan semut hitam (Dolichoderus sp.) kasta ratu, semut jantan, dan semut pekerja pada sarang buatan diketahui bahwa proses kolonisasi selalu diawali oleh kedatangan semut pekerja. Hasil pengamatan ini menunjukkan bahwa proses kolonisasi terjadi secara migrasi. Kolonisasi diawali oleh migrasi semut pekerja dari koloni yang lain ke sarang 
perlakuan. Semut pekerja, terutama yang bertugas mencari makanan aktif berpindah dari satu tempat ke tempat yang lain untuk mencari sumber makanan. Proses pencarian makanan atau survei semut pekerja menjadi titik awal terbentuknya koloni baru.

Pada hasil pengamatan perbandingan kehadiran semut hitam pada sarang buatan dengan perlakuan embun madu kutu putih dan madu lebah (Tabel 3) rata-rata kehadiran semut hitam pekerja pada sarang buatan dengan perlakuan lebah madu lebih tinggi dibandingkan rata-rata kehadiran semut hitam pekerja pada sarang buatan dengan perlakuan embun madu dari kutu putih, tingginya rata-rata kehadiran semut hitam pekerja pada sarang buatan perlakuan lebah madu yaitu 1190,4 ekor per sarang, rata-rata kehadiran semut hitam pekerja pada sarang buatan dengan perlakuan embun madu dari kutu putih yaitu 862,2 ekor per sarang (Tabel 3).

\section{KESIMPULAN}

Berdasarkan hasil pengamatan dan pembahasan disimpulkan sebagai berikut :

a. Semut hitam (Dolichoderus sp.) melakukan migrasi dengan lambat yang dilihat dari waktu yang dibutuhkan ratu untuk migrasi yaitu pada minggu ketiga pengamatan.

b. Pakan dari embun madu yang digunakan tidak efektif dalam membuat semut hitam membentuk koloni pada sarang buatan, dilihat dari jumlah kehadiran semut pekerja dan semut ratu pada sarang buatan.

c. Pakan madu dari lebah menarik kehadiran semut hitam pekerja lebih banyak dari embun madu dari kutu putih, karena aroma madu yang menyebar cepat dan kandungan gula pada madu yang tinggi.

\section{DAFTAR PUSTAKA}

Ho, C.T. and K.C. Khoo. 1997. Partners in Biological Control of Cocoa Pests: Mutualism between Dolichoderus thoracicus (Hymenoptera: Formicidae) and Cataenococus hispidus (Hemiptera:

Pseudococcidae). Bulletin of Entomological Research. 87: 461470.

Mele, V. P. dan N.T.T. Cuc. 2004. Semut Sahabat Petani: Meningkatkan Hasil Buah-buahan dan Menjaga Kelestarian Lingkungan Bersama Semut Rangrang. Diterjemahkan oleh Subekti Rahayu. World Agroforestry Centre. Jakarta.

Sulaiman, 2001. "Penggunaan Semut Hitam Dolichoderus thoracicus dalam Pengendalian Hama Tanaman Kakao Theobroma cacao". Laporan Penelitian. Departement of Plant Protection Faculty of Agriculture- 
University Putra Malaysia. Kuala

Lumpur.

Sulistyowati, E. 1988. Pengendalian

Biologis dan Prospeknya Pada Hama

Tanaman Kakao. Warta Balai

Penelitian Tanaman Kakao. Balai

Penelitian Perkebunan. Jember. 